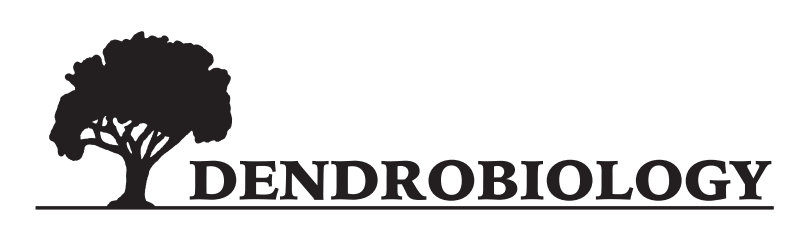

2017, vol. 78, 75-84

http://dx.doi.org/10.12657/denbio.078.008

\author{
Ren-bo Zhang, Gui-jie Ding*, Xiao-man Luo, Mo-fang Chen
}

\title{
Bivariate distribution characteristics of spatial structure in five different Pinus massoniana forests
}

\author{
Received: 30 March 2016; Accepted: 12 May 2017
}

\begin{abstract}
Bivariate distribution is an effective approach to spatial structure analysis. Combined with two of the three structure parameters (uniform angle index $(W)$, dominance $(U)$ and mingling $(M)$ ), the structural bivariate characteristics of five different Pinus massoniana forests were explored in this study. Our objective was to provide a theoretical direction for structure-based and detailed management in P. massoniana forests. The bivariate traits showed that mixed artificial or secondary forests predominated by $P$. massoniana trees do not typically achieve the highest mingling level. Trees under extreme mingling conditions were rare and typically comprised of non-dominant species instead of dominant ones in P. massoniana forests; these trees were generally overtopped and randomly distributed. Management implications can be extracted comparing the bivariate traits between all species and dominant species. The original community structure, development stage, and mixed-tree species number affect the univariate $M$ and, furthermore, the two bivariate $U-M$ and $W-M$ distributions in mixed forests. Forest type has little effect on all-species $W-U$ traits compared to those of the dominant species. $U-M$ traits should be adjusted first if the random frequency values are highest in $W-U$ and $W-M$ bivariate distribution, and it is necessary to determine whether these two bivariate traits shade the $W$ univariate. Adjustments made based on bivariate distribution can reveal poor frequency combinations for foresters to target; this allows the simultaneous adjustment of dual aspects of forest structure based on one bivariate index. Our results show that bivariate distribution may provide very useful information for the management of $P$. massoniana and other forests.
\end{abstract}

Keywords: Uniform angle index, mingling, dominance, structure-based forest management

Addresses: R. B. Zhang, G. J. Ding, X. M. Luo, College of Forestry, Guizhou University, Guiyang, China 550025; Research Center of Forest Resources and Environment in Guizhou Province, Guiyang, China 550025, e-mail: ddzrb@126.com, *e-mail: guijieding@126.com

R. B. Zhang, M. F. Chen, Department of Biology, Zunyi Normal College, Zunyi, China 563002

\section{Introduction}

Pinus massoniana Lamb. is tree species that is often cultivated in southern China. The area covered by $P$. massoniana is up to 12 million ha and accounts for $7.74 \%$ of the total arboreal forest area (Meng et al., 2014), making it the most common species in coniferous forests in China (Zhang, 2014). It is important for the Chinese government, especially in the south, to understand the spatial structure of $P$. massoniana forests.

Structure-based forest management (SBFM) is applied to foster healthy and stable forests (Hui et al., 2010) by focusing on stand structure rather than 
timber production (Gao et al., 2013). SBFM can improve forest quality by changing species composition and structural diversity (Bettinger \& Tang, 2015) and is an effective method of forest management. Under the SBFM concept, a healthy and stable forest is randomly distributed and with varied species and size differentiations (Chai et al., 2017). These three structural characteristics can be represented by a group of parameters based on the nearest neighborhood statistics: Uniform angle index $(W)$, dominance $(U)$, and mingling $(M)$ (Hui et al., 2010).

When the three parameters are not combined, they can only independently provide a single feature of forest structure. The three parameters are inherently independent and have the same five frequency values $(0.00,0.25,0.50,0.75$, and 1.00$)$, two of which can be combined to obtain three bivariate distributions (Li, 2013) to represent the spatial structural characteristics of forests. Each combination has 25 associations exploiting the spatial expressions of $W, U$, and $M$, and containing all of the information that can be provided by any pair of structural parameters (Li, 2013). Bivariate distribution can be used not only to analyze the similarities and differences between communities and populations, but also the structural differentiation between individuals of the same species (Li et al., 2014).

Previous research on bivariate distribution of community structures in forests has mostly centered around combined probability for heights and diameters (Hafley \& Schreuder, 1977; Rupšys \& Petrauskas, 2010; Zucchini et al., 2001), and has yielded a wealth of useful information for forest management. Current studies investigating $W, U$, and $M$ bivariate distribution (called "WUM bivariate distribution" from here on to distinguish it from the height-diameter bivariate distribution) are ongoing in Changbai Mountain (Li et al., 2012; Li et al., 2014; Li, 2013; Ni et al., 2014), Qinling Mountain (Chai et al., 2017; Zhang et al., 2015a; Zhang et al., 2014), Beijing Jiulong Mountain (Zhang et al., 2015b), and the coastline of Guangxi Province (Li et al., 2016).

Although WUM bivariate distribution is an effective analysis method for spatial forest structure, studies on WUM characteristics have been generally confined to the above regions in China; their effects in other areas or different forest types remain unclear. P. massoniana is an important tree species commonly cultivated in southern China, and understanding its
WUM traits can provide practical guidance for forest management. We established five different $P$. massoniana sites in Guizhou Province (southwestern China), and performed a WUM bivariate analysis based on SBFM to address three main issues: 1) Identifying the similarities and differences in WUM bivariate distribution between pure and mingled P. massonia$n a$ forests and other forest types; 2) identifying the WUM characteristics of dominant tree species in $P$. massoniana forests; and 3) identifying the valuable references that WUM characteristics can provide for structure-based, sustainable, and detailed management in P. massoniana and other forests. We hypothesized that WUM bivariate characteristics can simultaneously indicate the dual undesirable aspects of distribution pattern, mingling, and dominance traits in forests, thus providing useful guidance for forest management.

\section{Methods}

\section{Study sites}

Five different $P$. massoniana forests (Table 1) were established in Duyun City, Pingtang County (Qiannan Prefecture), and Rongjiang County (Qiandongnan Prefecture) in Guizhou Province. Guizhou Province $\left(24^{\circ} 30^{\prime}-29^{\circ} 13^{\prime} \mathrm{N}, 103^{\circ} 31^{\prime}-109^{\circ} 30^{\prime} \mathrm{E}\right)$ is located in a mountainous area in southwestern China belonging to the subtropical humid monsoon climate zone; this area has an average altitude of $1000 \mathrm{~m}$, temperature of $11.0-19.0^{\circ} \mathrm{C}$, and annual rainfall of $1100-1300 \mathrm{~mm}$; most of the area receives abundant rainfall, less sunshine, and more cloudy-rainy days throughout the year (Huang et al., 1988).

The P. massoniana forest mingled with Cunninghamia lanceolata Hook. (MF) was established in Zhaihao Township in Rongjiang County; the stands were artificially planted after slope reclamation by Rongjiang Afforestation Company in 1985. The share was $70.68 \%$ for P. massoniana and $29.02 \%$ for C. lanceola$t a$. The natural secondary pure $P$. massoniana forest (NSP) was established in Daping Town in Duyun City; the community was developed by natural regeneration after logging in 1990 and 1991. The share was $95.79 \%$ for $P$. massoniana. The pure artificial $P$. massoniana forest (MP) was established in Luobang Town in Duyun City; the stands were artificially

Table 1. Site traits of five Pinus massoniana forests

\begin{tabular}{lccccccc}
\hline \multicolumn{1}{c}{ Site } & Longitude $(\mathrm{E})$ & Latitude $(\mathrm{N})$ & Altitude $(\mathrm{m})$ & Slope aspect & Age (Yrs) & Average tree height (m) & Coverage \\
\hline MF & $108^{\circ} 34^{\prime} 51.16^{\prime \prime}$ & $26^{\circ} 12^{\prime} 07.73^{\prime \prime}$ & 488 & SE & 30 & 20.22 & 0.8 \\
NSP & $107^{\circ} 34^{\prime} 52.73^{\prime \prime}$ & $26^{\circ} 10^{\prime} 51.36^{\prime \prime}$ & 826 & W & $25-26$ & 15.99 & 0.7 \\
MP & $107^{\circ} 32^{\prime} 02.35^{\prime \prime}$ & $26^{\circ} 17^{\prime} 23.60^{\prime \prime}$ & 837 & E & 19 & 9.68 & 0.7 \\
MSB & $107^{\circ} 25^{\prime} 41.41^{\prime \prime}$ & $26^{\circ} 05^{\prime} 14.94^{\prime \prime}$ & 950 & NW & $24-25$ & 13.05 & 0.7 \\
MHB & $107^{\circ} 05^{\prime} 25.55^{\prime \prime}$ & $25^{\circ} 53^{\prime} 55.27^{\prime \prime}$ & 988 & E & $25-26$ & 10.55 & 0.9 \\
\hline
\end{tabular}


planted in an arid slope in 1996 and the share was $95.09 \%$ for $P$. massoniana. The natural secondary $P$. massoniana forest mingled with Liquidambar formosana Hance (MSB) was established in Pinglang Town in Duyun City. The share was $45.76 \%$ for P. massoniana and $39.59 \%$ for L. formosana. The P. massoniana forest mingled with Quercus fabri Hance (MHB) was established in Yazhou Town in Pingtang County; the stands were derived from aerial seeding after an artificial fire burn and then mingled with the native fire-tolerant Q. fabri. The share was $67.96 \%$ for $P$. massoniana and $29.90 \%$ for Q. fabri. The NSP and MP forests are pure forests, and the MF, MSB, and MHB forests are mixed forests. The NSP and MSB forests are natural secondary forests, and the MF, MP and MHB forests are artificial forests. All five sites are located in middle slopes and have not been managed since being established.

\section{Data collection}

One $50 \times 50 \mathrm{~m}$ plot was established at each site and subdivided into $2510 \times 10 \mathrm{~m}$ orderly numbered quadrants. Trees with diameter at breast height (dbh) of $\geq 5 \mathrm{~cm}$ were measured for $\mathrm{dbh}$ and the distances to the sample line were measured (angles were not measured between reference trees and neighbor trees). The species and number of trees with $\mathrm{dbh}<5$ $\mathrm{cm}$ were counted and recorded. Plants that could not be recognized immediately were brought back to the laboratory for identification, and voucher specimens were deposited in the herbarium at Zunyi Normal College ("ZY" in Index Herbariorum).

\section{Bivariate relative frequency}

The $W, U$, and $M$ values were calculated using Winkelmass 1.0 software (Gadow, 1998) and used to analyze the spatial structure according to methods described by Hui et al. (2010) and Li et al. (2012).

$W$ is an index used to describe the regularity between reference trees and their nearest neighbors. Hui et al. (2010) suggested that a reference tree with four nearest neighbors is optimal. It is defined as the proportion of the angles $\alpha$ that are smaller than the standard $\alpha_{0}\left(72^{\circ}\right)$, and expressed as follows:

$$
\mathrm{Wi}=\frac{1}{4} \times \sum_{j=1}^{4} Z i j
$$

$Z i j=1$ if $\alpha$-angle is smaller than $\alpha_{0}$, otherwise $Z i j=0$. The closer the $W i$ value is to 0 , the more regular the distribution pattern; conversely, as the Wi values approach 1 , the distribution pattern tends to be clumped.

$U$ is defined as the proportion of the $n$ nearest neighbors of a given reference tree that are smaller than the reference tree $i$, which is expressed as follows:

$$
\mathrm{Ui}=\frac{1}{4} \times \sum_{j=1}^{4} K i j
$$

$K i j=1$ if neighbor $j$ is greater than reference tree $i$, otherwise $K i j=0$. The closer the $U i$ value is to 0 , the more the tree $i$ tends to be dominant; conversely, as the $U i$ values approach 1 , the tree $i$ tends to be overtopped per the Kraft classes: dominant, co-dominant, intermediate, and overtopped (Jennings et al., 1999).

$M$ is defined as the proportion of the $n$ nearest neighbors that are a different species from the reference tree, which is expressed as follows:

$$
\mathrm{Mi}=\frac{1}{4} \times \sum_{j=1}^{4} V i j
$$

$V i j=1$ if neighbor $j$ is not the same species as reference tree $i$, otherwise $V i j=0 . M i$ values close to 0 indicate a low level of species mingling, while Mi values close to 1 indicate a high level of species mingling.

The WUM bivariate relative frequencies were calculated using the method of Li et al. (2012). The WUM indices were calculated for each tree in a plot and ranked in Excel software (Microsoft Corp., Seattle, WA, USA), then the impact of an index's rank on another index was determined. To eliminate edge effects, data in the buffer area $(5 \mathrm{~m}$ from the borderline) were deleted prior to ranking. The number of trees with different index combinations was divided by the tree number in the core area considered to produce a bivariate distribution of structural parameters. A total of 25 frequency values were mapped to $3 \mathrm{D}-\mathrm{XYY}$ bar charts in Origin software (Origin Lab Corp., Northampton, MA, USA) and their ecological implications were summarized as discussed below.

\section{Results}

\section{U-M bivariate distribution}

The $U-M$ frequency values of all species were 0.0887 and 0.0319 (Table S1) at the structural combination $(M=0.75 \& 1.00, U=0.75 \& 1.00)$ in the NSP and MP forests, respectively - both greater than those (0.0197 and 0.0177) at the structural combination ( $M=0.75 \& 1.00, U=0.00 \& 0.25)$, suggesting more overtopped individuals than dominant ones in well-mingled structural units in pure forests. Compared to pure forests, the dominant $U-M$ values of all species were slightly greater than overtopped ones in the MF (0.1720 vs 0.1656$)$, MSB (0.2464 vs 0.2391$)$, and MHB (0.1977 vs 0.1860) forests when well-mingled, suggesting a quite different trend. 


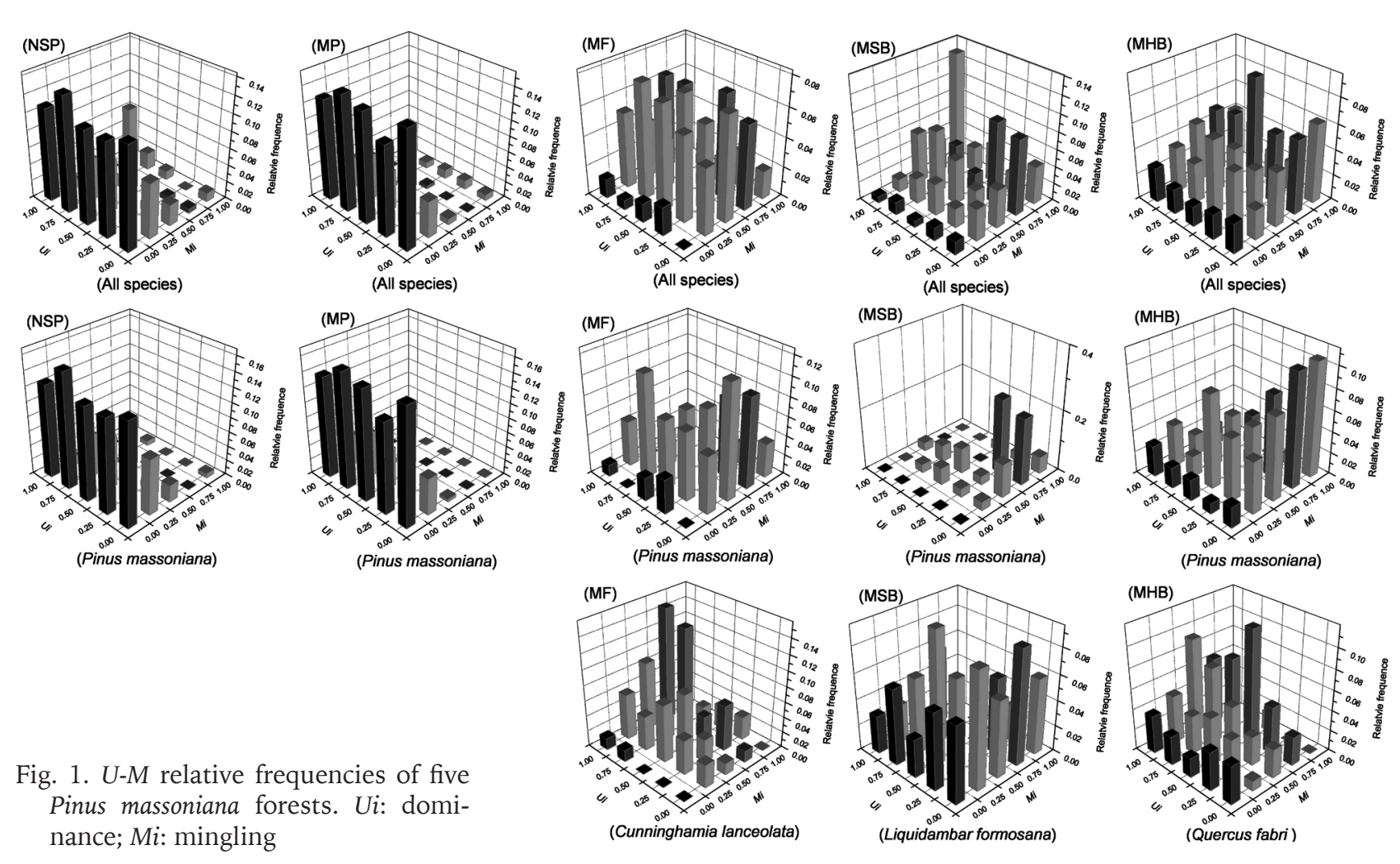

The $U-M$ bivariate distributions of $P$. massoniana were similar to those of all species in the NSP and MP forests (Fig. 1) because the shares of $P$. massoniana were both greater than $95 \%$ in the two pure forests. As expected, this was not observed in the mixed forests.

The dominant $(U=0.00 \& 0.25) \quad U-M$ frequency values of $P$. massoniana were much greater than those of overtopped values $(U=0.75 \& 1.00)$ when $M=0.75$ and 1.00 in the MF and MHB forests (Fig. $1)$; this was not the case for the main associated tree species (C. lanceolata or $Q$. fabri), suggesting that individuals can readily dominate for $P$. massoniana but were overtopped for associated species in well-mingled structral units. The $U-M$ frequency values of $P$. massoniana mainly occurred at the structural combination $(M=0.75, U i=0.00 \& 0.25)$, and the dominant value (0.2353) of $L$. formosana was greater than overtopped one (0.0882) when $M=0.75$ and 1.00 in the MSB forest (Fig. 1, Table S1), suggesting that both $P$. massoniana and $L$. formosana easily dominate when highly mingled. These results suggest that the dominant tree species are either dominant or overtopped under well-mingled structural units in mixed $P$. massoniana forests.

\section{W-M bivariate distribution}

Whether it was all species or dominant species, the maximum $W-M$ frequency values converged at random axes $(W=0.50)$ and then declined along both sides in all five communities (Fig. 2). The minimum values were at $W=0.00$ and $W=1.00$ (few exceptions), suggesting abundant random trees and few absolutely regular/clustered trees at different mingling levels.

As mingling degree increased $(M=0.00 \rightarrow 1.00)$, the $W-M$ values of all species increased and then decreased in the MF forest, increased along the main distribution axis $(W=0.50)$ in the MSB forest, fluctuated along the main distribution axis in the MHB forest, and generally decreased in the two pure forests.

In the MP forest, the $W-M$ frequency sum of all species at the structural combination $(W=0.75 \&$ $1.00, M=0.75 \& 1.00$ ) was 0.0319 , which is higher than that of regular and well-mingled value (0.0035) (Fig. 2, Table S2), suggesting that the mingled state of the clustered trees was better than that of the regular ones. The all-species $W-M$ frequency sum of the clustered and well-mingled value (0.0099) was smaller than the regular and well-mingled value (0.0148) in the NSP forest, suggesting that the mingled state of the regular trees was better than the clustered ones.

Similar to the $U-M$ traits, the $W-M$ bivariate distributions of $P$. massoniana were consistent with those of all species in the NSP and MP forests. The most distinct disparity was that the $W-M$ values of all species were greater than those of $P$. massoniana at the structural combination $(M=1.00 \& W=0.50)$ (Fig. 2 ), suggesting that the individuals of non-dominant tree species were more likely to be randomly distributed than $P$. massoniana under extreme mingling conditions. 

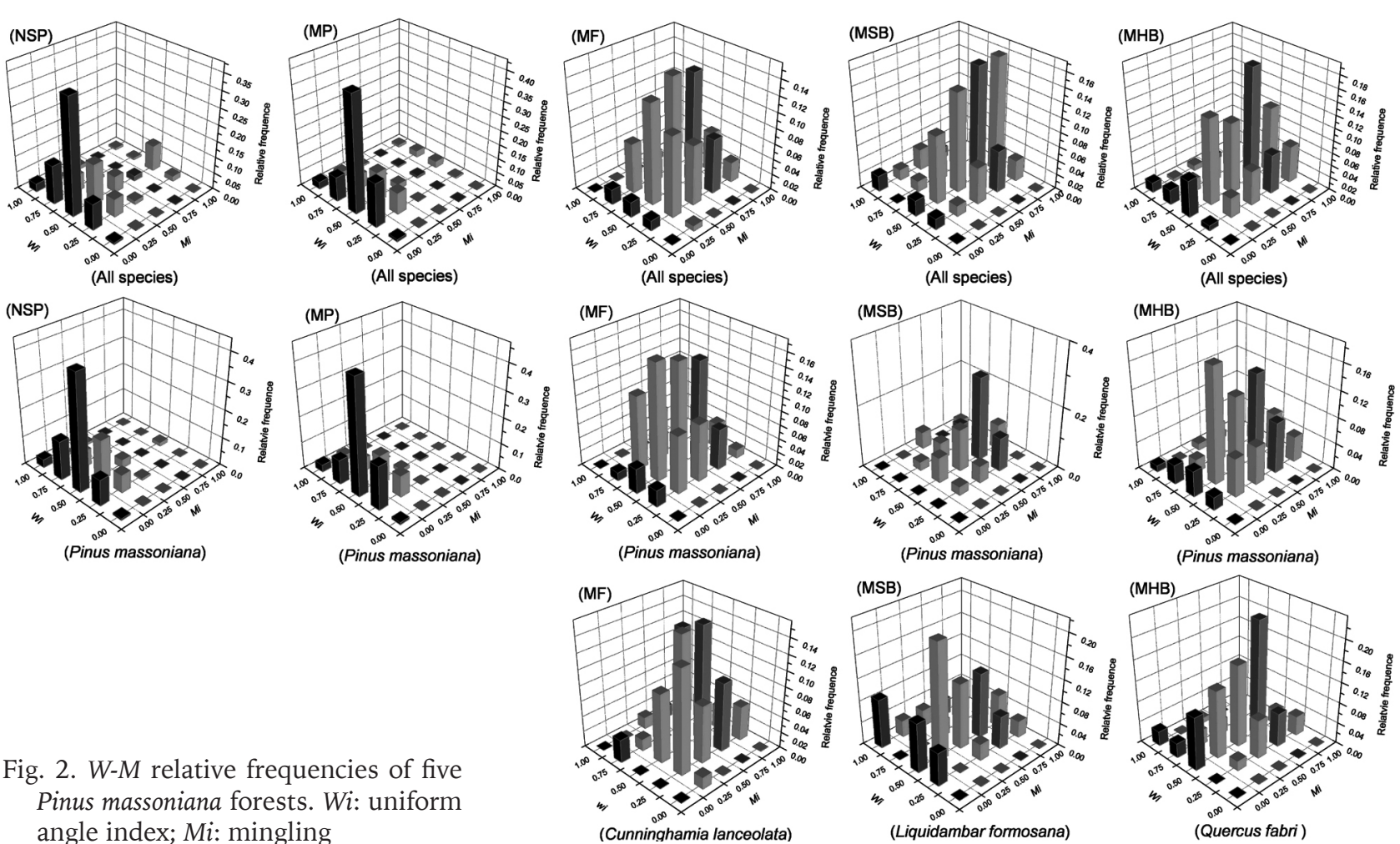

Pinus massoniana forests.
angle index; $M i$ : mingling

The $W-M$ values of $L$. formosana were much greater than those of $P$. massoniana (the total was 0 ) or all species when $M=0.00$ in the MSB forest (Fig. 2), suggesting that the mingling status of $P$. massoniana was better than that of the associated species. The $W-M$ values of $Q$. fabri mainly increased at a random axis $(W=0.50)$ with increasing mingling but suddenly decreased when $M=1.00$, suggesting that the individuals of $Q$. fabri are rarely randomly distributed under extreme mingling conditions (as opposed to the other four mingling levels).

\section{W-U bivariate distribution}

Similar to the $W-M$ distribution, the maximum $W-U$ frequency values converged at random axes
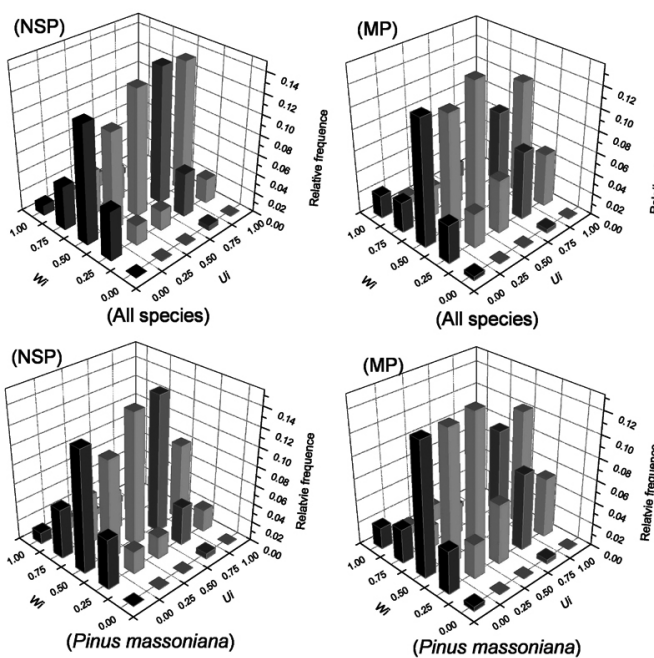

(Pinus massoniana)
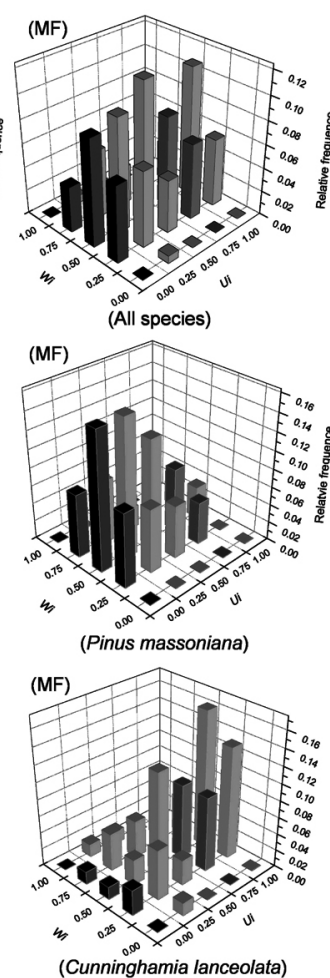
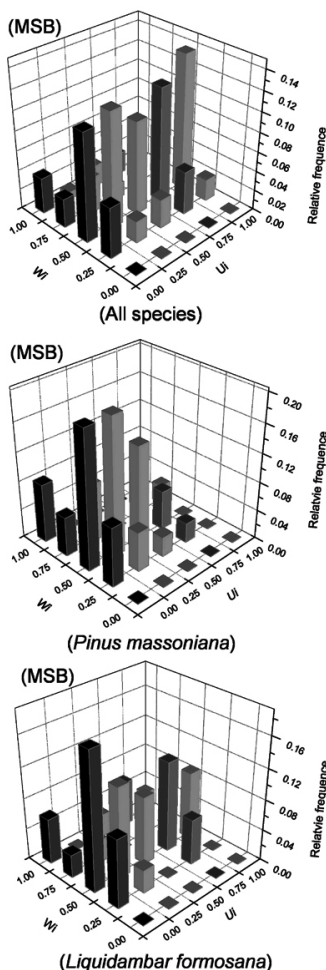
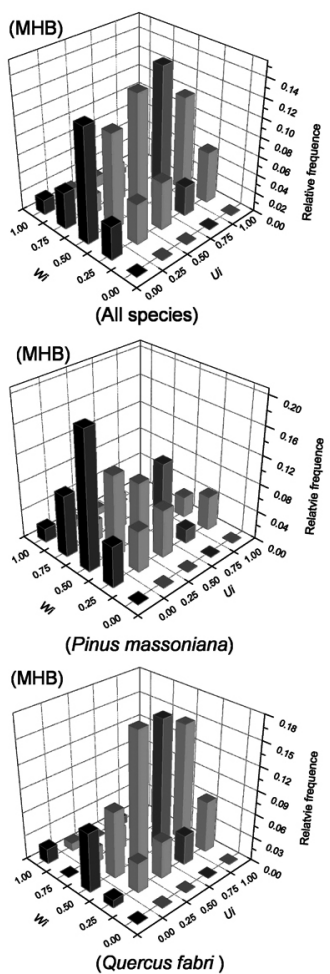

Fig. 3. W-U relative frequencies of five Pinus massoniana forests. Wi: uniform angle index; $U i$ : dominance

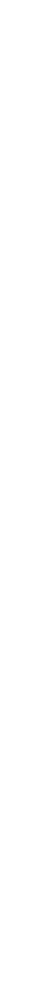


$(W=0.50)$ and then decreased along both sides whether it was all species or dominant species in pure and mixed stands (Fig. 3). The minimum values were at $W=0.00$ and $W=1.00$ (few exceptions). The $W-U$ values of all species were fairly similar at the same $W$ level, suggesting that the dominant trees are close to overtopped ones at different distribution patterns.

The $W-U$ bivariate distributions of $P$. massoniana were similar to those of all species in the two pure forests for the afore-mentioned reason. The $W-U$ values tended to be overtopped ( $U \rightarrow 0.75$ and 1.00) from $U=0.50$ for associated species (C. lanceolata or Q. fabri) but dominant ( $U \rightarrow 0.25$ and 0.00$)$ for P. massoniana in the MF and MHB forests (Fig. 3), suggesting that most individuals are dominant for $P$. massoniana but overtopped for the associated species at various $W$ levels. The $W-U$ values of $P$. massoniana and $L$. formosana both tended to be dominant in the MSB forest, suggesting that most individuals of these two species are dominant at different $W$ levels.

\section{Discussion}

\section{WUM traits applicable for the detailed forest management in small structural units}

The WUM bivariate distribution provides synthesized structural information regarding the mingling between tree species, distribution patterns and competition among individuals, all of which have important implications for forest management. Foresters can formulate corresponding policies by analyzing the changes in spatial forest structure before and after thinning per the WUM information, which can help to regulate the harvest intensity and ensure sustainable management (Li, 2013).

WUM parameters are based on small structural units (five trees in each unit), which makes elaborate adjustments to forest management practices possible. An ideal forest can be managed via selective cutting using WUM bivariate traits. That is, if the WUM distributions are not converged upon the higher mixture ( $M$ axis is from 0.50 to 1.00 ) and dominance ( $U$ axis is 0.00 or 0.25 ) and the random distribution axis ( $W$ is 0.50 ) in a forest, the frequency values of the two bivariates can be adjusted across many small structural units to achieve detailed management. Hui et al. (2010) suggested that individuals with a 0.00 or $0.25 \mathrm{M}$ value should be considered as potential regulating objects.

\section{Mixed artificial or secondary forests predominated by $P$. massoniana trees do not have highest mingling levels}

Whether it was all species or dominant species, the $U-M$ values decreased gradually as mingling level decreased $(M=1.00 \rightarrow 0.00)$ at the same $U$ level in mixed forests (Li et al., 2012; Li et al., 2014; Ni et al., $2014)$; the $W-M$ values were generally maximal when mingling was extreme $(M=1.00)$. Our results for mingled $P$. massoniana forests were not similar, however. Whether it was all species or dominant species, the $U-M$ or $W-M$ values were always not maximal at extreme mingling $(M=1.00)$ in the three mixed sites in our study (Figs. 1 and 2), but in fact often smaller than those under strong mingling $(M=0.75)$, moderate mingling $(M=0.50)$, and even slight mingling $(M=0.25)$. This suggests that $P$. massoniana-dominant communities usually do not achieve the highest mingling levels, although P. massoniana prevails as a pioneer tree species. Their WUM traits should be improved based on the SBFM concept.

\section{U-M traits should be adjusted first if the random frequency values are highest in $\mathrm{W}-\mathrm{U}$ and $\mathrm{W}-\mathrm{M}$ bivariate distribution}

The frequency values of random distribution in the three mixed forests we observed were highest in both $W-M$ and $W-U$ bivariate traits (Figs. 2 and 3 ), so we would assert that the $U-M$ trait should be adjusted first to manage these forests. Most P. massoniana trees with three nearest neighbors of the same species $(M=0.25)$ should be cut down in the MF and MHB forests (Fig. 1) while in the MSB forest most P. massoniana trees should be retained because their $U-M$ distribution is ideal. For the main associated tree species, many overtopped $(U=1.00 \& 0.75)$ C. lanceolata trees should be cut down although they have high mingling $(M=0.75)$ in the MF forest (Fig. 1 ), but they can be retained if their dominance can be improved after some of their nearest neighbors are cut down. Many associated trees with dbh smaller than its four (or three) nearest neighbors $(U=1.00$ or 0.75 ) and with two nearest neighbors of the same species $(M=0.50)$ could be cut down (Fig. 1) if this would create ideal $U-M$ distributions in the MSB and MHB forests; if not, further means should be considered.

Any management procedure based on WUM traits can be effectively computer-simulated prior to implementation. The main undesirable frequency combination (low dominance and mingling) based on the SBFM concept can be targeted to improve forest structures. For example, the poorest $U-M$ frequency 
of $P$. massoniana converged on $M=0.25$ in the MF forest (Figure 1); after the 44 P. massoniana trees under $M=0.25$ (Table S4) were removed from the simulation, the dominance and mingling of $P$. massoniana markedly improved (Figure S1 in comparison to Figure 1). The dominance and mingling of all species would also increase (Table S5). The dominance of the main associated tree (C. lanceolata) also slightly increased. The mingling of $C$. lanceolata slightly decreased under these conditions, but was still within a reasonable range.

Similarly, after the $11 \mathrm{~L}$. formosana trees under the combination $U=0.75$ and $M=0.00,0.25$, or 0.50 (Table S6) were removed from the simulated MSB forest (referred to as Plan 1 in Table S5 to distinguish from another adjustment plan for MSB), the dominance and mingling of all species and the target species improved (Table S5, Figure S1). If the $14 P$. massoniana trees under $M=0.25$ and $U=0.50,12 Q$. fabri trees under $M=0.50$ and $U=0.75$, and 13 Q. fabri trees under $M=0.50$ and $U=1.00$ (Table S7) were removed from the simulated MHB forest, the mingling of all species (or the target species) improved (Table S5, Figure S1). The dominance of the Q. fabri trees also increased under these conditions. Although the dominance of all species and P. massoniana slightly decreased, they remained reasonable.

In short, our results suggest that adjustment procedures based on WUM traits can improve forest structures under the SBFM concept with only slight (inconsequential) loss. These adjustments simultaneously target two aspects of the forest structure, which lends them notable advantages over adjustment means based on univariate distributions.

After the above-mentioned simulated adjustment, the $U-M$ values still did not converge on the highest mingling axes $(M=1.00)$ in the three mixed forests (Figure S1). This supports our viewpoint that mixed artificial or secondary forests predominated by $P$. massoniana trees do not have the highest mingling levels. In other words, any adjustment of mingling is a longterm task in these mixed forests.

\section{Management implications can be extracted per WUM traits among all species and dominant species}

The frequency value of the structural combination $(U=1.00 \& M=1.00)$ of all species suddenly increased comparing to that of dominant species in the NSP forest (Fig. 1), suggesting that some trees of non-dominant species were absolutely overtopped under the extreme mingling conditions. This clearly occurred in the MSB forest, as well. The maximum frequency of all species occurred at the structural combination $(M=1.00, U=1.00)$ while the value of dominant species was zero in the MSB forest (Fig. 1 , Table S1), suggesting that many small trees of non-dominant species were completely overtopped to the point where they were entirely surrounded by other species in the community. This may have occurred due to small, light-preferring trees being surrounded by other tree species as they are rare individuals, leaving extremely mingled trees more susceptible to overtopping (Zhang et al., 2015b). These small trees of non-dominant species surrounded by other species should not be cut down during future management considering the mingling level. If these trees (Table S8) were cut down (referred to as Plan 2 in Table S5), the mingling of all species or the target species substantially decrease (Table S5) - this is, of course, not ideal under the SBFM concept.

Although the maximal $W-M$ value of associate species (L. formosana) occurred at slight mingling $(M=0.25)$ in the MSB forest so it is not ideal according to SBFM, the $W-M$ distribution does not need to be adjusted considering the management costs at the present time because the all-species $W-M$ distribution is ideal (Fig. 2). The W-M distribution of the all-species converged to the low mixture in the MF and MHB forests; their W-M traits should be improved. The $W-M$ distribution of the dominant species (P. massoniana) instead of the associated species (C. lanceolata or Q. fabri) should be adjusted in both forests considering their respective $W-M$ traits (Fig. 2).

The $W-U$ distribution of all three mixed forests should be improved because their frequency values did not converge upon higher dominance (Fig. 3). The $W-U$ frequency of $P$. massoniana should not be adjusted in the three forests considering their $W-U$ traits (Fig. 3) while the associated species should be adjusted in the MF and MHB forests (but not the MSB forest).

\section{Original community structure, development stage, and mixed-tree species number affect univariate $M$ and, furthermore, the two bivariate U-M and $\mathrm{W}-\mathrm{M}$ distributions in mixed forests}

Different individuals from the same species may violently compete for resources because they have similar growth needs, resulting in self thinning. Trees in this situation tend to disperse from each other and increase the mingling degree of the forest in which they are located (Mackenzie et al., 2003). Although forests also experience human disturbance to varying extent (Li et al., 2012), Korean pine broad-leaved forests are natural and have been close to recovery for nearly 40 years resulting in higher development stage and higher mingling; their $U-M$ 
and $W-M$ frequency values are maximum under extreme mingling $(M=1.00)$. Our target trees species were planted on a reclamation slope (MF forest) or burned hillside (MHB forest) as pioneer species, and the sites were extensively damaged before afforestation. There are few other tree species, and community development was relatively brief (25-30 years), so the mingling was low and the frequency values were not maximal under extreme mingling. The MSB forest was more natural and its primary vegetation was not extensively damaged when the stands were formed, so its mingling conditions were favorable. In short: The original structure and development stage of the community affect the $U-M$ and $W-M$ characteristics in mixed forests. Li et al. (2012) and Zhang et al. (2015b) also posited that spatial structural traits are correlated with the community origin and succession stage in forests.

The number of mingled tree species is also a factor worth considering. Compared to the abundant dominant and associated tree species in the Korean pine mixed forests (Li et al., 2012), P. massoniana were mainly mingled with only one associated species in the MF and MHB forests we observed, so individuals could not readily enter the extremely mingled state. Thus, the frequency values were smaller when $M=1.00$. There were more associated trees in the MSB forest resulting in higher frequencies under extreme mingling, but the frequency values of $P$. massoniana and the main associated tree species were still low when $M=1.00$ (Fig. 1), suggesting that most individuals that were under extreme mingling conditions were derived from non-dominant species. These results indicate that the number of mingled tree species also affect the $U-M$ and $W-M$ traits.

\section{Mingling state affects W-U traits of different dominant trees}

P. massoniana was generally dominant, and the main associated tree species was generally overtopped at different $W$ levels in the MF and MHB forests. These species were both dominant in the MSB forest. Li et al. (2014) similarly found that some associated species were dominant and some were overtopped at different $W$ levels in Korean pine broad-leaved forests. The mingling state may have had some effect on these observations. There were few associated trees besides $P$. massoniana and the main associated tree species in the MF and MHB forests, resulting in a direct competition between the two species where one was dominant and the other was overtopped. Many associated tree species were present in the MSB forest, resulting the dominance of $P$. massoniana and the main associated species compared to other associated species.

\section{Forest type barely affects all-species $\mathrm{W}$-U traits but not dominant species}

Unlike the $U-M$ and $W-M$ distributions, the $W-U$ features of all species in the pure forests were not distinguishable from those in the mixed forests we observed (Fig. 3). The $U$ values of all species were similar at the same $W$ level, suggesting that the forest type had little impact on the $W-U$ traits of all species. Previous researchers have made similar observations (Li et al., 2012; Li et al., 2016; Zhang et al., 2015a; Zhang et al., 2014; Zhang et al., 2015b). Compared to all species, the $U$ values of the dominant species were generally different at the same $W$ level, suggesting that the individuals from the same species were either dominant or overtopped under different distribution patterns in the mixed forests.

\section{Randomly distributed reference trees are highest in the communities across different forest types}

The highest frequency values of $W-M$ and $W-U$ bivariate distributions converged upon random axes $(W=0.50)$ and then decreased along both sides (Figs. 2 and 3) whether in regards to all species or dominant speices. Again, similar observations were made in previous research (Chai et al., 2017; Li et al., 2012; Li et al., 2014; Zhang et al., 2014; Zhang et al., $2015 \mathrm{~b})$. This result indicates that the proportion of randomly distributed reference trees was highest in the communities across different forest types.

The natural forests (NSP and MSB forests) and artificial forests (MF, MP, and MHB forests) exhibited substantial randomness in the forests we observed as well as in L. principis-rupprechtii forests (Zhang et al., 2014) and P. orientalis plantations (Zhang et al., 2015b). Although Kenkel (1988) states that surviving individuals are highly regularly distributed because mortality is differentiated at different competition stages in community development and other researchers have asserted that density-dependent mortality drives surviving trees towards regularity (Boncina et al., 2007; Lutz et al., 2014; Zingg \& Ramp, 2004) - many other studies have shown that the community distribution pattern becomes random under succession (Kint, 2005; Pommerening, 2002; Zhao et al., 2009) due to random mortality (Szmyt, 2012). Other studies have also suggested that the sensitivity of $W$ to discrepancy is lower in nearest neighborhood statistics (Aguirre et al., 2003; Mason et al., 2007; Neumann \& Starlinger, 2001). Further research is warranted to determine whether the two bivariate characteristics $(W-U \& W-M)$ would shade the univariate $W$ traits. 


\section{Conclusion}

In this study, we investigated WUM bivariate distribution to find that trees under extreme mingling conditions are rare and usually derived from non-dominant species instead of dominant species in $P$. massoniana forests. These trees are generally overtopped and randomly distributed. Management implications can be extracted by comparing the WUM traits between all species and dominant species. The $U-M$ traits should be adjusted first if the random frequency values are highest in $W-U$ and $W-M$ bivariate distribution. Adjustments based on bivariate distribution can elucidate the poorest frequency combination for foresters to target; dual aspects of the forest structure can be amended based on a single bivariate index in practice. The original community structure, development stage, and mixed-tree species number affect the univariate $M$ and, furthermore, the two bivariate $U-M$ and $W-M$ distributions in the mixed forests. Comprehensive structural information based on bivariate distributions has notable potential implications for the management of $P$. massoniana and other forests.

The all-species $W-U$ traits were similar in all the sites, including the WUM distributions referred in this paper and taken from the literature, across different forest types both pure and mixed. Additional studies should be carried out to determine whether the community type has a significant impact on all-species $W-U$ distribution. The $W-M$ and $W-U$ frequency values were highest under random distribution in all the sites (again including our WUM distributions and those of previous researchers). Similar studies should be performed to test this phenomenon in other community types, especially in clustered/regularly distributed communities, to determine whether the two bivariate traits shade the $W$ univariate.

\section{Acknowledgements}

This study was financially supported by the Major Special Projects in Guizhou Province under the "Industrialization key technology research and demonstration and multi-objective directional cultivation in P. massoniana forests" program (2012) 6001 and the Major Forestry Projects in Guizhou Province under the "Key technology research and demonstration of improving stand quality in $P$. Massoniana timber forests" program (2010) 03.

\section{References}

Aguirre O, Hui G, von Gadow K \& Jiménez J (2003) An analysis of spatial forest structure using neighbourhood-based variables. Forest Ecology and Management 183: 137-145.

Bettinger P \& Tang M (2015) Tree-level harvest optimization for structure-based forest management based on the species mingling index. Forests 6 : 1121-1144.

Boncina A, Kadunc A \& Robic D (2007) Effects of selective thinning on growth and development of beech (Fagus sylvatica L.) forest stands in south-eastern Slovenia. Annals of Forest Science 64: 47-57.

Chai Z, Sun C, Wang D, Liu W \& Zhang C (2017) Spatial structure and dynamics of predominant populations in a virgin old-growth oak forest in the Qinling Mountains, China. Scandinavian Journal of Forest Research 32: 19-29.

Gadow Kv (1998) Das winkelmass-ein strukturparameter zur beschreibung der individualverteilung in waldbeständen. Centralblatt für das Gesamte Forstwesen 115: 19.

Gao G, Ding G, Wang H, Zang Y, Liang W, An Y \& He Y (2013) Short Communication. Restoring monoculture plantation using stand spatial structure analysis. Forest Systems 22: 147-151.

Hafley WL \& Schreuder HT (1977) Statistical distributions for fitting diameter and height data in even-aged stands. Canadian Journal of Forest Research 7: 481-487.

Huang WL, Tu YL \& Yang L (1988) Guizhou vegetation. Guizhou People's Press, Guiyang, China.

Hui GY, Zhao ZH \& Hu YB (2010) A guide to structure-based forest management. Chinese Foretry Press, Beijing, China.

Jennings SB, Brown ND \& Sheil D (1999) Assessing forest canopies and understorey illumination: canopy closure, canopy cover and other measures. Forestry 72: 59-74.

Kenkel N (1988) Pattern of self-thinning in jack pine: testing the random mortality hypothesis. Ecology 69: 1017-1024.

Kint V (2005) Structural development in ageing temperate Scots pine stands. Forest Ecology and Management 214: 237-250.

Li Y, Hui G, Zhao Z \& Hu Y (2012) The bivariate distribution characteristics of spatial structure in natural Korean pine broad-leaved forest. Journal of Vegetation Science 23: 1180-1190.

Li Y, Hui G, Zhao Z, Hu Y \& Ye S (2014) Spatial structural characteristics of three hardwood species in Korean pine broad-leaved forest-Validating the bivariate distribution of structural parameters from the point of tree population. Forest Ecology and Management 314: 17-25.

Li YF (2013) The bivariate distribution of forest stand spatial structral parameters. Chinese Academy of Forestry, pp. 57-61. 
Li YF, Wang L, Yu SF, Ye SM \& Lu DD (2016) Spatial structure of Syzygium hancei community along coastline of Guangxi. Chinese Journal of Ecology 35: 726-732.

Lutz JA, Larson AJ, Furniss TJ, Donato DC, Freund JA, Swanson ME, Bible KJ, Chen J \& Franklin JF (2014) Spatially nonrandom tree mortality and ingrowth maintain equilibrium pattern in an old-growth Pseudotsuga-Tsuga forest. Ecology 95: 2047-2054.

Mackenzie A, Ball AS \& Virdee SR (2003) Ecology. Science Press, Beijing.

Mason W, Connolly T, Pommerening A \& Edwards C (2007) Spatial structure of semi-natural and plantation stands of Scots pine (Pinus sylvestris L.) in northern Scotland. Forestry 80: 567-586.

Meng J, Lu Y \& Zeng J (2014) Transformation of a degraded Pinus massoniana plantation into a mixed-species irregular forest: impacts on stand structure and growth in southern China. Forests 5: 3199-3221.

Neumann M \& Starlinger F (2001) The significance of different indices for stand structure and diversity in forests. Forest Ecology and Management 145: 91-106.

Ni R, Baiketuerhan Y, Zhang C, Zhao X \& von Gadow K (2014) Analysing structural diversity in two temperate forests in northeastern China. Forest Ecology and Management 316: 139-147.

Pommerening A (2002) Approaches to quantifying forest structures. Forestry 75: 305-324.

Rupšys P \& Petrauskas E (2010) The bivariate Gompertz diffusion model for tree diameter and height distribution. Forest Science 56: 271-280.
Szmyt J (2012) Spatial structure of managed beech-dominated forest: applicability of nearest neighbors indices. Dendrobiology 68: 69-76.

Zhang GG, Wang DX, Chai ZZ, Zhang CS, Liu WZ \& Zhang SZ (2015a) Distribution characteristics of two typical natural forest spatial structure parameters in Xiaolongshan. Forest Research 28: 531-537.

Zhang GG, Wang DX, Chai ZZ, Zhu HY \& Zhang CS (2014) Bivariate distribution of spatial structure in Larix principis-rupprechtii plantation in the middle section of Qinling Mountains. Journal of Northwest Sci-Tech University of Agriculture and Forestry 42: 33-40.

Zhang JQ (2014) Study on diameter structure regularity on Masson pine plantation in northern Fujian Mountain. Qinhai Forestry Science \& Technology 4: 20-22.

Zhang LJ, Hu YB, Zhao ZH \& Sun ZZ (2015b) Spatial structure diversity of Platycladus orientalis plantation in Beijing Jiuling Mountain. Chinese Journal of Ecology 34: 60-69.

Zhao ZH, Hui GY, Yuan SY, Liu WZ \& Wang RX (2009) Spatial structure characteristics of the natural Quercus acutidentata forests. Chinese Forestry Science 45: 1-6.

Zingg A \& Ramp B (2004) Thinning and stem quality in pure and mixed beech (Fagus sylvatica L.) stands, Vol. 1: Improvement and silviculture of beech. Proceedings from the th International Beech Symposium. IUFRO Research Group 1.10.00. Teheran, Iran, pp. 196-180.

Zucchini W, Schmidt M \& Von Gadow K (2001) A model for the diameter-height distribution in an uneven-aged beech forest and a method to assess the fit of such models. Silva Fennica 35: 169-183. 